\title{
Multiscale and Correlative Analytical Electron Microscopy of Extraterrestrial Minerals
}

\author{
Mihaela Albu ${ }^{1 *}$, Harald Fitzek ${ }^{1}$, David Moser ${ }^{2}$, Gerald Kothleitner ${ }^{1,2}$ and Ferdinand Hofer ${ }^{1,2}$ \\ ${ }^{1}$ Graz Centre for Electron Microscopy, Graz, Austria, 2 Institute of Electron Microscopy and Nanoanalysis, TU Graz, Graz, Austria
}

\section{OPEN ACCESS}

Edited by:

Rosa De La Torre Noetzel, Instituto Nacional de Técnica Aeroespacial (INTA), Spain

Reviewed by: Svatopluk Civis, J. Heyrovsky Institute of Physical Chemistry (ASCR), Czechia Akos Kereszturi, Hungarian Academy of Sciences (MTA), Hungary

*Correspondence: Mihaela Albu mihaela.albu@felmi-zfe.at

Specialty section: This article was submitted to Astrobiology,

a section of the journal Frontiers in Astronomy and Space Sciences

Received: 20 March 2020 Accepted: 27 October 2020 Published: 19 November 2020

Citation: Albu M, Fitzek $H$, Moser D, Kothleitner $G$ and Hofer $F$ (2020) Multiscale and Correlative Analytical Electron Microscopy of Extraterrestrial Minerals. Front. Astron. Space Sci. 7:544331. doi: 10.3389/fspas.2020.544331
This paper presents a unique correlative microscopic method for the structural characterization of extraterrestrial minerals. A fragment from the pallasite Seymchan meteorite that consists of olivine grains mixed into a metallic iron matrix with variable nickel content was studied from mm-down to nm-size by using the Raman Imaging and Scanning Electron Microscopy and analytical scanning transmission electron microscopy. Hyperspectral fast acquisition for energy-dispersive X-ray spectroscopy mapping of a couple of mm2 large area correlated with additional hyperspectral Raman analysis of smaller regions in the same area on one hand, and hyperspectral analytic STEM investigations at the atomic resolution, on the other hand, provided valuable information about the chemical composition, bonding, and crystallography. The analysis revealed particles of troilite, schreibersite, and forsterite but also regions of mixed iron oxides, carbonates, and amorphous carbon as well as plessite regions with nanometre-sized taenite needles dispersed in the kamacite matrix.

Keywords: Seymchan meteorite, correlative microscopy, scanning electron microscopy, Raman, scanning transmission electron microscopy, energy dispersive X-ray spectroscopy, electron energy loss spectroscopy

\section{INTRODUCTION}

Pallasites are exquisite meteorites made of millimeter- to centimeter-sized olivine grains and $\mathrm{FeNi}$ metal alloys. The pallasites comprising the main group (PMG), about $90 \%$ of all pallasite meteorites found on Earth, have similar composition and are thought to originate from a single asteroid body whereas the other $10 \%$ are probably derived from five or six other asteroids. The classification of meteorites, that provides information on the geological past, is historically based on the Fe content extracted via wet chemistry analysis and electron microprobe. The analysis of oxygen isotope or the isotope ratios of other noble gases $(\mathrm{He}, \mathrm{Ne}, \mathrm{Ar}, \mathrm{Kr}$ ) that have been trapped into the stone, the analysis of the rare Earth elements content and crystal pattern information are other methods used to classify a meteorite. Unlike chondritic meteorites that are fragments of asteroids, which avoided melting and differentiation, the pallasites undergone thermal metamorphism that produced metal separation.

The primitive (unaltered) chondrites contain complex mixtures of micrometer sized magnesian olivine and low-Ca pyroxene, amorphous ferromagnesian silicates, Fe, Ni-metals, sulphides and organic phases. These meteorites also contain fractions of material that was probably vaporized and recondensed during high-temperature transient heating events associated with the formation of chondrules and refractory inclusions (Kereszturi et al., 2015; Bizzaro et al., 2017). The differentiated meteorites, on the other hand, are fragments of asteroids that experienced chemical and physical changes that led to a separation of the metallic part from silicates leading to metallic core and silicate mantle. They are considered core-mantle mixtures, and could come from many different asteroid 
bodies with different cooling and shock histories (Fritz et al., 2017; Hunt et al., 2018). Microstructural, chemical, and isotopic analyzes of meteorites provide unique information on their origin, thermochemical and shock history (Hunt et al., 2018; Gyollai et al., 2019); The Meteorite Exchange, (2014). Furthermore, their specific chemical composition, which contain elements throughout the entire periodic table (albeit in ppm concentration), is very important for the astrobiological assessments of the necessary conditions for primordial life in the Universe. It has been shown that interstellar medium, asteroids, comets, and meteorites host the organic matter necessary for life. It is also assumed that the impact of such objects (asteroids) brought volatile organic matter to the ancient Earth. For example, meteorites are considered major sources of carbon and reactive phosphorus (pyrophosphate, triphosphate)-a likely requirement for the emergence of life (Domagal-Goldman and Wright 2016). For the progress in astrophysics and astrobiology, a detailed investigation of meteorites down to the nano- and atomic range became therefore necessary.

Seymchan, a differentiated meteorite classified as heterogeneous pallasite consists of regions of pure metal-plessite (FeNi alloy-estimated to $\sim 34.6$ vol\%) and pure silicate $(\sim 60.4 \mathrm{vol} \%)$ but also mesosiderite regions (Kichanov et al., 2018). Moreover, chromite phosphate and troilite phases $(\mathrm{FeS})$ are present with a fraction of about $5 \mathrm{vol} \%$. This meteorite is the only pallasite that contains all three morphologies of olivine grains, olivine clusters and large metal veins (Bösenberg et al., 2012; Kichanov et al., 2018). With a Ni content of $9.51 \mathrm{wt} \%$, the Seymchan was first classified as an IEE-related iron meteorite (Scott and Watson 1976) but was later, after a new expedition in 2004 where additional fragments were found, identified as a main-group anomalous pallasite (Van Niekerk et al., 2007; Wilson, 2012). Its Widmanstätten pattern-cooling rate was estimated to be $7.1+1.2 \mathrm{~K} / \mathrm{Myr}$ (Yang et al., 2010). Besides Fe and $\mathrm{Ni}$ other elements with trace concentrations (ppm) such as: Co (0.48 wt\%), Cr, Cu, Ga, As, W, Ir, and Au were identified by neutron-activation analysis (Wasson and Wang, 1986).

Regular bulk and microstructure investigations of meteorites involve X-ray and infrared spectroscopy (Skulteti et al., 2020a; Skulteti et al., 2020b), optical microscopy and Raman analysis (Kereszturi et al., 2017; Tulej et al., 2017), metallographic methods, X-ray tomography and other synchrotron radiation techniques. Furthermore, bulk analyzes performed using both X-ray methods and infrared spectroscopy help to link the meteorites to their parent asteroids and therefore also support the next space missions. However, each method has advantages and disadvantages. For example, the metallographic methods are destructive but offer microstructure information down to $\mu \mathrm{m}$ range, on the other hand X-ray tomography and the synchrotron radiation relied methods are nondestructive but most of them only offer bulk-like information (Kichanov et al., 2018; Blukis et al., 2020). Few methods based on neutron scattering can reach a higher spatial resolution (Lehmann et al., 2017). Nano-SIMS (secondary ion mass spectrometry) and RIMS (resonance ionization mass spectrometry), however, deliver exact chemical information down to nanometer scale but no information about the crystallography (Ott and Hope, 2006). In the last decade, the analytical scanning and transmission electron microscopy (SEM and TEM) investigations have proven to be an important tool for both microstructure and crystallographic investigations of extraterrestrial minerals (Lin et al., 1977; Vollmer et al., 2014; Lo et al., 2019; Vollmer et al., 2019).

In this work in addition to SEM and TEM, we apply a new correlative microstructure analysis of the Seymchan meteorite by using the Raman Imaging and Scanning Electron Microscopy RISE (Jiruše et al., 2014; Schmidt et al., 2019). The RISE method is a seamless combination of two techniques, that offers the possibility of imaging by SEM and chemical analysis with the attached Raman microscope. In addition, a modern X-ray silicon drift detector that enables hyperspectral analysis in a comparatively short time rounds up the correlative investigations. Furthermore, transmission electron microscopy in scanning mode along with analytical capabilities such as electron energy loss (EELS) and energy dispersive X-ray spectroscopy (EDXS), provided information about both crystal structure and chemical composition down to atomic resolution and with the best detection limit for trace elements measured with EELS that exist at this moment.

\section{MATERIALS AND METHODS}

A small fragment of the Seymchan meteorite metallic part was cut and prepared for SEM and Raman investigations. The surface was first polished with standard procedure and etched in order to identify the plessite regions. Usually, to avoid charging effects, a coating $(\mathrm{C}$ or $\mathrm{Au})$ needs to be applied prior to SEM investigations. However, in this particular case, the preparation of the sample surface needs to be coating-free for additional Raman spectroscopy investigation of the same area. Focused ion beam (FIB) lamellas were additionally prepared from plessite regions for the analytical STEM analysis.

The SEM imaging was performed using the scanning electron microscope Sigma 300 VP (Zeiss, Oberkochen, Germany) and the chemical analysis with the attached Raman microscope from WITec (Ulm, Germany). The electron microscope is also equipped with a silicon drift detector from Oxford (UK) for EDXS that allows for fast acquisition of spectra and maps (Schmidt et al., 2019). The energy resolution of the Oxford EDS detector as specified by the provider is: at $\mathrm{C} \mathrm{Ka}-50 \mathrm{eV}$, $\mathrm{F} \mathrm{Ka}-57 \mathrm{eV}, \mathrm{Mn} \mathrm{Ka}-127 \mathrm{eV}$. The spatial resolution-as simulated with the Monte Carlo software (Drouin et al., 2007) - is between $100 \mathrm{~nm}$ (for $\mathrm{Fe}$ and $\mathrm{Ni}$ ) and $300 \mathrm{~nm}$ (for O, $\mathrm{Mg}, \mathrm{P}$, and $\mathrm{Si}$ ). The Raman measurements were performed using a $532 \mathrm{~nm}$ laser with the laser power reduced to $2.5 \mathrm{~mW}$ in order to minimize sample damage. The integration time was adjusted for every spectrum to give a reasonable signal to noise ratio and standard spectrum correction, such as cosmic ray removal and background correction were performed directly in the instrument software (Project FIVE, Witec).

TEM investigations such as: Energy filtered transmission electron microscopy (EFTEM), high resolution high angular annular dark field imaging (HAADF), EELS and EDXS spectroscopy, were performed on FIB lamellas. The lamellas 
were investigated in TEM and STEM mode by HAADF imaging and hyperspectral X-ray mapping. For TEM investigations a Tecnai F20 microscope was used whereas the STEM investigations were performed with an aberration corrected FEI Titan G3 60-300 microscope operated at $300 \mathrm{kV}$. This microscope is equipped with a Schotky emitter, a monochromator, a Super X detector (Chemi-STEM technology with four silicon drift detectors surrounding the sample) for EDXS (Schlossmacher et al., 2010), and with a Dual EELS Quantum Gatan Imaging Filter (GIF) for EELS (Gubbens et al., 2010). A direct electron detection camera (Gatan-K2) allows for detection of EELS spectra with even higher energy resolution and detection limits. We used the Gatan's Digital Micrograph Software to process the micrographs, EELS and EDXS spectra, and the VELOX software by Thermo Fisher Scientific to acquire and process the hyperspectral EDXS mapping. The k-method was used for the quantification of the EDXS spectra (Goldstein et al., 1986).

\section{RESULTS}

Previous neutron tomography investigation showed that the metal component of the Seymchan meteorite consist of a dendrite-like complex network of metals veins (Kichanov et al., 2018). We performed our microscopic investigation in a large metallic region as depicted on the optical micrograph in Figure 1A, with focus on plessite areas (FeNi-rich) and areas with mixed $\mathrm{Fe}-\mathrm{Ni}-\mathrm{P}, \mathrm{Fe}$-sulfate, -oxide, -hydroxide, and -carbonate.

The inset on the SEM image in Figure 1C depicts one plessite area from which a lamella was prepared by FIB. STEM micrographs and EDXS maps from plessite areas are presented in Figures 2B,D,E. These areas contain needle-like Nirich-taenite particles embedded into a kamacite matrix. The taenite needles of about $50-100 \mathrm{~nm}$ in diameter and 100-700 nm in length were studied by EDXS. The needles contain Fe (43.7 \pm $7 \mathrm{wt} \%)$, Ni (54.4 $\pm 8.8 \mathrm{wt} \%)$, and other elements with very low concentrations C: $0.72 \pm 0.09 \mathrm{wt} \%$, Si $0.81 \pm 0.2 \mathrm{wt} \%$, P: $0.20 \pm$ 0.04 wt $\%, \mathrm{Co}: 0.2-0.55 \pm 0.09 \mathrm{wt} \%$ and $\mathrm{Cu}: 0.5 \pm 0.06$. The $\mathrm{Ni}$ and $\mathrm{P}$ contents in the kamacite grains however, vary from 4.00 to $7.50 \pm 1.5 \mathrm{wt} \%$ and 0.09 to $0.23 \pm 0.02 \mathrm{wt} \%$, respectively. Low concentrations of $\mathrm{C}:<0.69 \pm 0.1 \mathrm{wt} \%, \mathrm{Si}<0.43 \pm 0.15 \mathrm{wt} \%$, and Co: $\sim 1.2 \pm 0.25 \mathrm{wt} \%$ were also found. The $\mathrm{Si}$ concentration is higher in the taenite needles while Co is dispersed in the kamacite phase. However, the $\mathrm{Co}-\mathrm{K} \alpha$ peak in the EDXS spectra is overlapping with the $\mathrm{Fe}-\mathrm{K} \beta$ peak and due to the fact that the energy resolution in EDX is not sufficient to separate the peaks, it is difficult to extract the exact intensity without multiple fitting. The $\mathrm{P}-\mathrm{K}$ peak in the EDXS spectra could only be clearly visible after long acquisition time of the spectrum image and addition of the spectra over large regions of kamacite- and taenite phase. It has to be noted that the SuperX detector also offers a better detection of all elements since we have four detectors surrounding the sample, thus detection of trace elements is possible.

The electron energy loss spectroscopy (EELS) investigations definitively revealed the low concentration of Co $(<1 \mathrm{wt} \%)$ dispersed in the kamacite matrix (Figure 2C) and of Si mainly in the taenite needles. An energy shift of about $1.0 \mathrm{eV}$ toward lower energy was measured for the $\mathrm{Ni}-\mathrm{L}_{3}$ ionization edge (ionization energy of the subshell L3 of the $\mathrm{Ni}$ atoms at $855 \mathrm{eV}$ ) in the taenite phase, thus confirming the different bonding of $\mathrm{Ni}$ in the two phases. It has to be noted that the low concentrations of Co could only be demonstrated by using the direct electron detection camera since its sensitivity is definitely higher than ordinary cameras used in electron microscopy.

The high-resolution STEM image from taenite needles and matrix is shown in Figure 2G. The fast Fourier transform (FFT) image calculated from an image at higher magnification, enables the measurement of the distance between the atomic columns in a certain orientation relative to the electron beam. The kamacite matrix was described in the literature as $a$-Fe with a disordered cubic structure $(4 / \mathrm{m}-32 / \mathrm{m}, a=2.86 \AA)$. We indeed observed the strained structure on the high-resolution images due to the collision history of the meteorite, but also due to the presence of impurities. The FFT image (Figure 2H) from a region of Figure 2G at higher magnification matches the mentioned body centered cubic structure in the [111] zone axis. The element profile in Figure 2J over one needle (Figure 2I) confirms the relationship between $\mathrm{Fe}$ and $\mathrm{Ni}$ in taenite.

A region containing $\mu \mathrm{m}$ large particles that have been revealed by etching the surface, was analyzed in SEM by EDXS mapping (Figure 3; Supplementary Figure S1). We identified the particles to be schreibersite $(\mathrm{Ni}, \mathrm{Fe})_{3} \mathrm{P}$ and one forsterite $\left(\mathrm{Mg}_{2} \mathrm{SiO}_{4}\right)$ (or ringwoodite-high pressure modification of olivine-cubic crystal structure). The schreibersite particles have dimension between $200 \mathrm{~nm}$ and $2 \mu \mathrm{m}$ and show elliptical, spherical and needle-like shapes while the forsterite particle is about $2 \mu \mathrm{m}$ large and has a triangle morphology. Their location into the metallic kamacite region and the chemical composition suggest them to be presolar grains. However, we cannot measure their isotopic signature in SEM or STEM.

$\mathrm{Si}$ and $\mathrm{Mg}$ condensate as forsterite and enstatite and are thought to be present in O-rich circumstellar shell of giant stars and in planetary nebulae (Molster et al., 2002a; Molster et al. 2002b; Molster et al. 2002c; Suh 2002). The silicates can be crystalline and amorphous; thicker and cooler circumstellar shells would favor crystalline silicates. Presolar silicates are not often observed in meteorites because the silicates are more susceptible to metamorphism and chemical changes than presolar carbonaceous and oxide grains (Lodders and Amari, 2005). Aqueous alteration for example erases the presolar isotopic signatures in the silicates if the parent meteorite body experienced much aqueous exposure. It is also difficult to locate the presolar silicate among abundant solar system silicate that are major constituents of meteorites, except when the particles are embed into metallic matrix as in the case of Seymchan meteorite. Forsterite particles were only measured by $\mathrm{O}$-isotope ion imaging with the NanoSIMS so far (Messenger et al., 2003). Iron, on the other hand, form FeNi alloy or condensates as troilite and schreibersite but these phases have not yet been directly identified in the dusty circumstellar shells of M-giants because of the very low infrared signal in spectra with a low resolution. However, for spectra acquired with the Infrared Space 

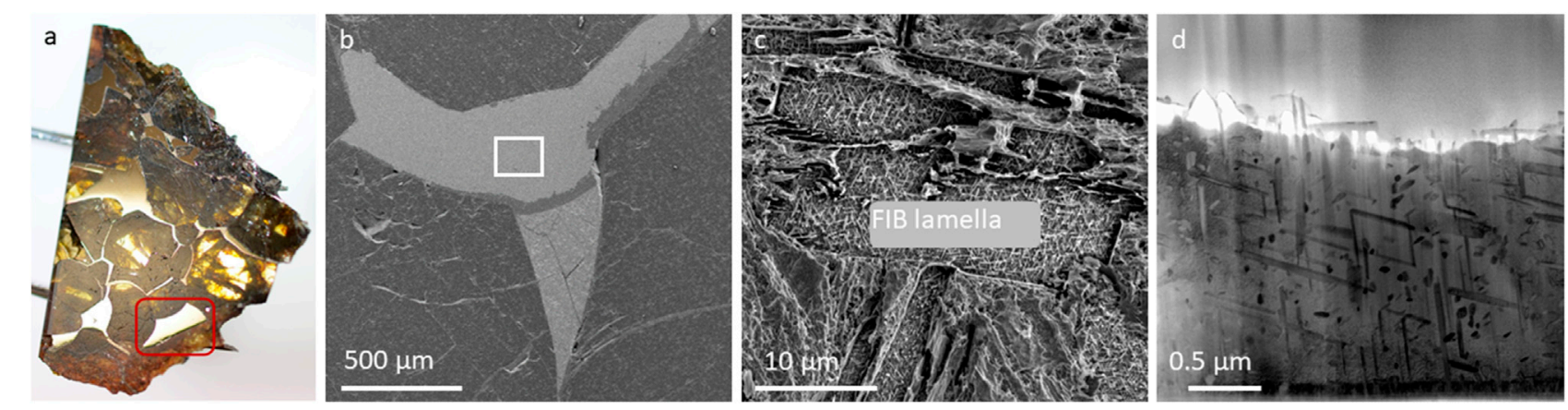

FIGURE 1 | (A) Optical microscopy image of the Seymchan meteorite fragment of approximatively $2 \mathrm{~cm}^{2}$, (B) SEM image at low magnification, (C) SEM image of the etched surface with the inset indicating the plessite region from where a FIB lamella was cut, and (D) STEM image of the FIB lamella.
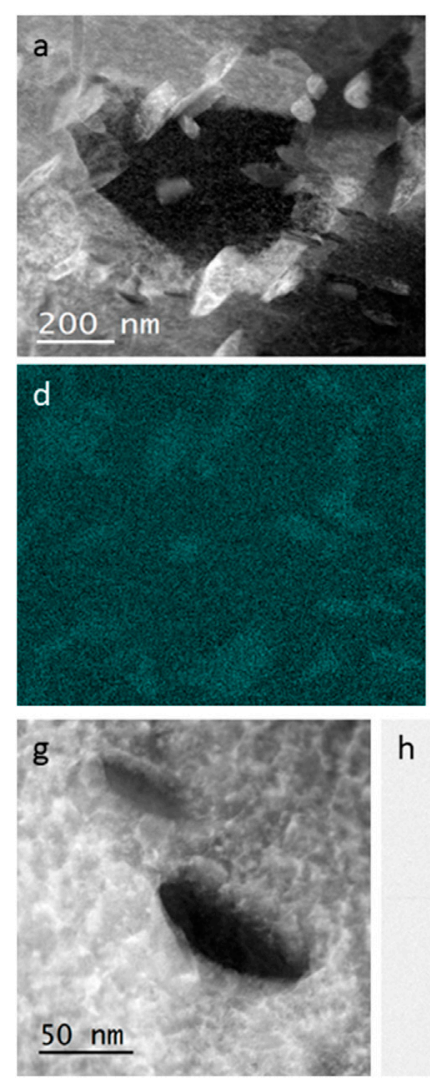

$\mathrm{h}$
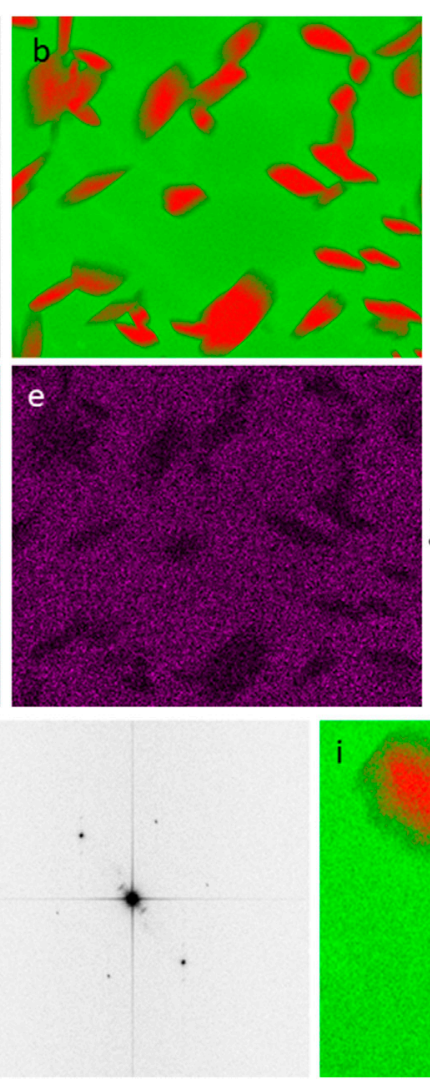
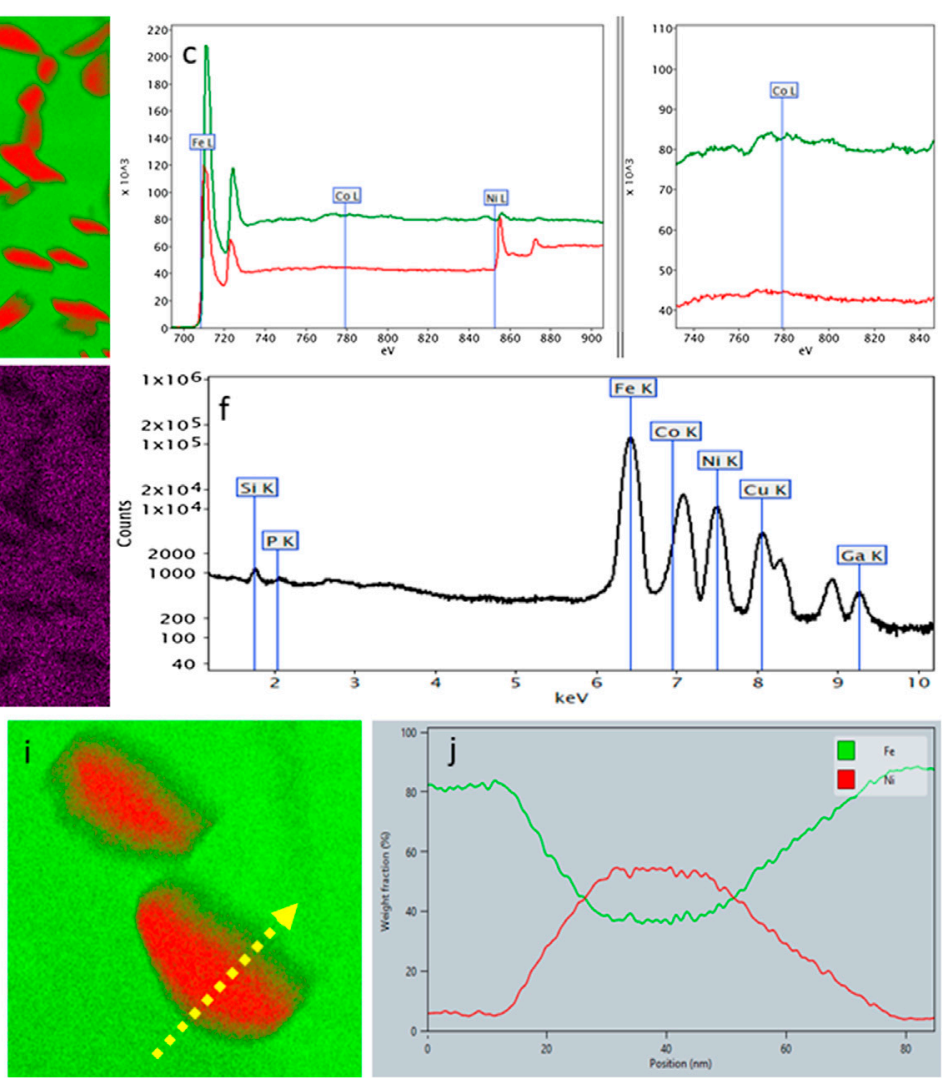

FIGURE 2 | (A) HAADF image of taenite needles in kamacite matrix; (B) composite image of EDXS maps: red-Ni and green-Fe, (C) EELS spectrum from the matrix (note the low Co signal), (D) Si EDXS maps, (E) Co SI EDXS map, (F) EDXS spectrum sum over the whole area (note the low P peak), (G) HAADF image of taenite needles in kamacite matrix, (H) Fast Fourier Transform of an area at higher magnification in (G) that indicates the [111] zone axis of cubic kamacite; (I) composite image of EDXS maps: red-Ni and green-Fe, $(\mathbf{J})$ element profile over taenite needle and kamacite phase (concentrations in wt\%).

Observatory at intermediate resolution, Kemper et al. estimated the contribution of non-spherical metallic iron to the near-infrared spectrum from a giant branch star (Kemper et al., 2002). Amorphous and/or graphitic carbon, is also believed to be present around many C-stars (Swart et al., 1983; Blanco et al., 1994).

A multiscale analysis using SEM-EDXS and Raman microscopy is shown in Figure 4. Starting from the large scale
EDXS-mapping (Figure 4A) an interesting $\mathrm{P}$-containing region was chosen for further analysis. In the small scale EDXSmapping a predominantly Fe-containing phase, a mixed $\mathrm{Fe}-\mathrm{Ni}-\mathrm{P}$ phase and some oxide-phases are apparent. Focusing in further the Raman analysis (Figure 4B), note that on the right-hand side spectra with similar composition have been averaged according to the color of their position 

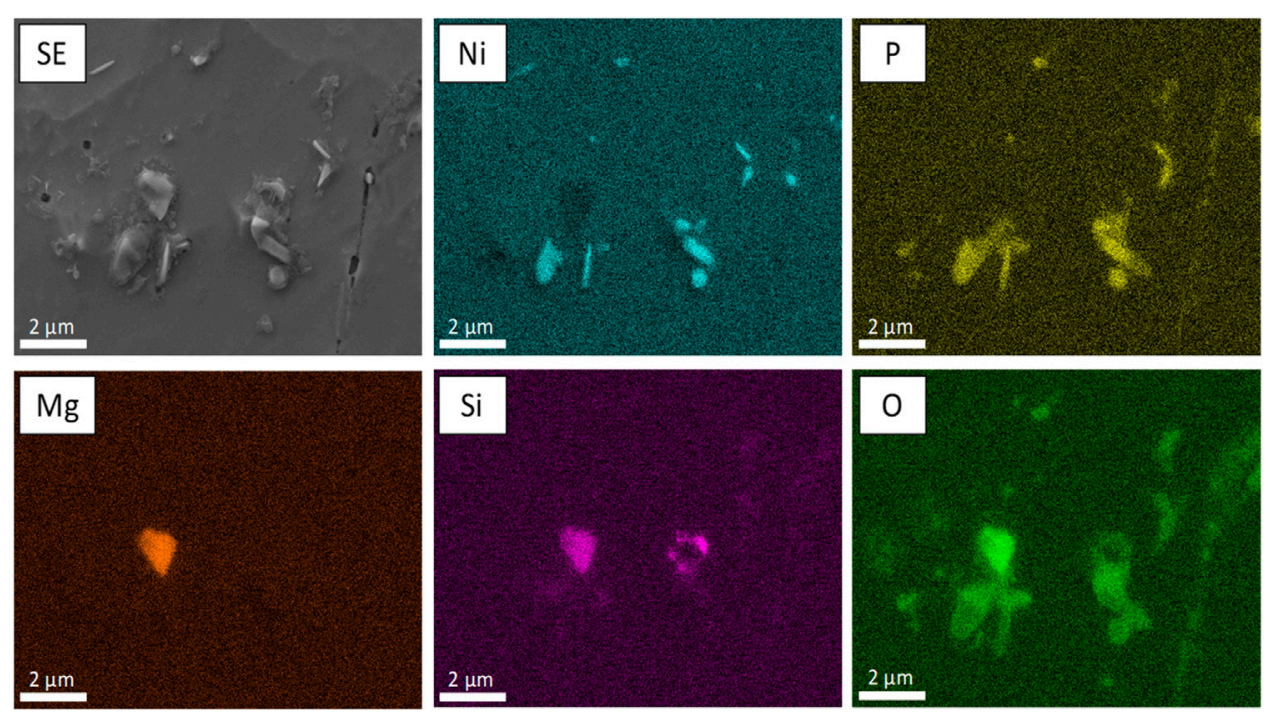

FIGURE 3 | SEM, EDXS Maps of a particle group containing a $\mathrm{Mg}_{2} \mathrm{SiO}_{4}$ particle (forsterite phase) and schreibersite (Ni,Fe) 3 P - $2 \mu$ m sized particles.

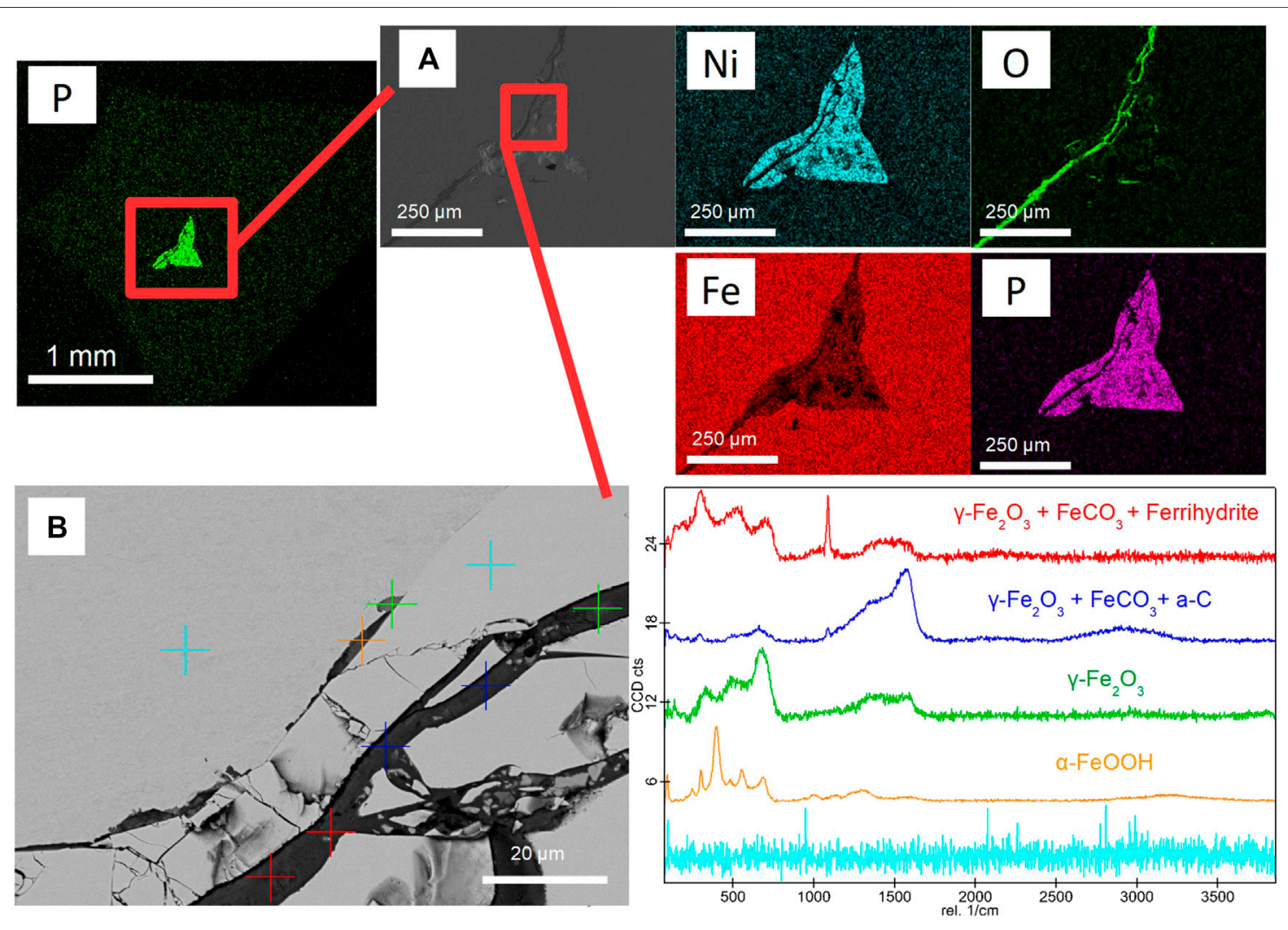

FIGURE 4 | Correlative Raman-SEM-EDX analysis of a Fe-Ni-P inclusion. (A) SE-image and EDXS-mapping of the whole inclusion. (B) Raman point measurements of the matrix materials and the oxygen rich veins.

indicator on the left, both the Fe- and $\mathrm{Fe}-\mathrm{Ni}-\mathrm{P}$ phase show no Raman signal indicating predominantly metallic phases. In the oxide-phase on the other hand a complex composition of multiple different materials is revealed by Raman. The phase contains iron oxide $\left(\gamma-\mathrm{Fe}_{2} \mathrm{O}_{3}\right.$ maghemite), iron hydroxides (ferrihydrite and goethite), iron carbonate and amorphous carbon. The spectral interpretation is based on reference spectra from (Hanesch, 2009). 


\section{DISCUSSION}

The goal of the measurement was actually to identify and localize presumable elements with trace concentrations $(\mathrm{Ca}, \mathrm{Cr}, \mathrm{Ti}, \mathrm{Al}, \mathrm{Co}, \mathrm{Si}$, $\mathrm{P}, \mathrm{Ga}, \mathrm{As}, \mathrm{W}, \mathrm{Ir}, \mathrm{Au})$ that have been confirmed by bulk measurements using the neutron-activation technique. Our microscopes are well suited with some of the best equipments for this type of analytical investigations: SuperX detector for EDXS detection and a DualEELS spectrometer and a K2 electron direct detection camera for EELS. Therefore, we were able to measure the Co content $(<1.00 \mathrm{wt} \%)$ and $\mathrm{Si}(<1.00 \mathrm{wt} \%)$ with EELS, and $\mathrm{Co}, \mathrm{Si}$, and $\mathrm{P}(<0.25 \mathrm{wt} \%)$ with EDXS. Also, we measured with the EDXS a broad triangle-like feature centered around $\mathrm{Ar}-\mathrm{K}(3 \mathrm{keV})$ peak. This feature appeared in the measurements performed for this meteorite at longer acquisition times and is slightly pronounced for the kamacite region. Our findings are in excellent agreement with the research on kamacite formation proposed by Goldstein and Doan (1972).

They established that below $7 \mathrm{wt} \% \mathrm{Ni}$ kamacite is formed by only one reaction path, $\gamma$ (taenite) $\rightarrow \alpha$ (kamacite) $+\gamma$. The phases with low concentration of $\mathrm{Ni}$ (5-3-5.9 wt\% or 5.8-6.5 wt\%) known as hexahedrites and hexaoctahedrites are described by this reaction. However, the equilibrium nucleation temperature for the kamacite was shown to be greatly increased by phosphorus presence. Above $7 \mathrm{wt}$ $\% \mathrm{Ni}$, kamacite is formed by either of two reaction paths depending on the $\mathrm{P}$ content. The first reaction path is the same as for lower concentrations of Ni: $\gamma \rightarrow \alpha+\gamma$ and is preferred at low P contents. At higher $\mathrm{P}$ contents $(0.2 \mathrm{wt} \%)$ the reaction path: $\gamma \rightarrow \gamma+\mathrm{Ph}$ (phosphide, $\left.(\mathrm{FeNi})_{3} \mathrm{P}\right) \rightarrow \alpha+\gamma+\mathrm{Ph}$ controls the formation of kamacite.

The plessite regions we investigated in STEM showed an average concentration of $\mathrm{Ni}$ lower than $7 \mathrm{wt} \%$, however some small kamacite grains contain slightly higher concentrations than $7 \mathrm{wt} \%$. The crystal structure of these small kamacite grains differs from the cubic bcc $a-F e$. The $h k l$ values we measured on the FFT, however, do not correspond to any known allomorph phase of $\mathrm{Fe}$ on Earth, but correspond to the metastable tetragonal iron found in other meteorites and it is considered to be a transitional state in the transformation of $\gamma$-phase alloy into $\alpha$-phase alloy (Ramsden and Cameron, 1966). Furthermore, the schreibersite particles we found by etching the pure kamacite regions, and the concentration of $0.2 \mathrm{wt} \%$ of $\mathrm{P}$ indicated that the formation of some kamacite phase also take place by the second reaction path $\gamma+\mathrm{Ph} \rightarrow \alpha+\gamma+\mathrm{Ph}$.

The RISE investigations of metallic parts from the Semchan meteorite, revealed particles of troilite, schreibersite and forsterite but also regions of mixed iron oxides, carbonates and amorphous carbon.

Assessing the morphology and composition of those particles, and the fact that were incorporated into the metallic kamacite matrix we assume them to have a presolar origin. The presence of presolar grains in the Seymchan meteorite was not indicated so far. Given that is the only meteorite that contains all three morphology types of olivine and the presolar grains we suspect, further detailed investigations by NanoSIMS should be considered.

\section{CONCLUSION}

A correlative investigation by using the method RISE and scanning transmission electron microscopy was applied to investigate the Seymchan meteorite. Valuable information about the morphology, chemistry and crystallography from millimeter down to nanometer sizes was acquired.

The analyses revealed nanometer sized taenite needles dispersed in the kamacite matrix. The taenite needles showed a very low content of silicon and the kamacite a very low content of cobalt and phosphorus. Moreover, due to the collision history of the meteorite and the presence of trace elements in the matrix, the crystal structure of the kamacite is highly defective and stressed. Additionally, presolar grains in the Seymchan meteorite and regions of iron- oxide, carbonate, and hydroxides as well as amorphous carbon were observed.

\section{DATA AVAILABILITY STATEMENT}

The original contributions presented in the study are included in the article/supplementary materials, further inquiries can be directed to the corresponding author.

\section{AUTHOR CONTRIBUTIONS}

MA performed high resolution STEM and wrote the manuscript, HF and DM performed SEM and Raman investigations, FH designed the experiment and all co-authors corrected and improved the manuscript.

\section{FUNDING}

RISE was enabled by the project "HRSM-Projekt ELMINet Graz-Korrelative Elektronenmikroskopie in den Biowissenschaften" (i.e., a cooperation within "BioTechMed-Graz," a research alliance of the University of Graz, the Medical University of Graz, and Graz University of Technology), which was financed by the Austrian Federal Ministry of Education, Science and Research (BMBWF). The combination with the EDX detector could be realized by the project "Innovative Materialcharakterisierung" (SP2016-002-006), which is part of "ACR Strategisches Projektprogramm 2016" of the Austrian Cooperative Research (ACR). The STEM investigations received financial support by the Austrian Science Fund (FFG): SP2018-003-006 (Microstructure of 3D printed metallic parts), the "Zukunftfonds Steiermark" for the purchase of the K2-camera through the "ASTEM upgrade" project \#9016, and from the European Union's Horizon 2020 research and innovation program under grant agreement No. 823717-ESTEEM3.

\section{ACKNOWLEDGMENTS}

The authors would like to thank Martina Dienstleder and Sebastian Rauch for sample preparation.

\section{SUPPLEMENTARY MATERIAL}

The Supplementary Material for this article can be found online at: https://www.frontiersin.org/articles/10.3389/fspas.2020.544331/ full\#supplementary-material 


\section{REFERENCES}

Bizzarro, M., Connelly, J. N., and Krot, A. N. (2017). "Chondrules: ubiquitous chondritic solids tracking the evolution of the solar protoplanetary disk," in Formation, evolution, and dynamics of Young solar systems. Astrophysics and space science library. Editors M. Pessah and O. Gressel (Cham, Switzerland: Springer), Vol. 445. doi:10.1007/9783-319-60609-5_6

Blanco, A., Borghesi, A., Fonti, S., and Orofino, V., (1994). Amorphous carbon and silicon carbide grain mixtures in the envelopes of carbon stars. Astron. Astrophys. 283, 561-566. doi:10.1007/978-94-009-3033-9_16

Blukis, R., Pfau, B., Günther, C. M., Hessing, P., Eisebitt, S., Einsle, J., et al. (2020). Nanoscale imaging of high field magnetic hysteresis in meteoritic metal using X-ray holography. G-cubed. 21 (8), 1-13. doi:10.1029/ 2020GC009044

Boesenberg, J. S., Delaney, J. S., and Hewins, R. H. (2012). A petrological and chemical reexamination of Main Group pallasite formation. Geochim. Cosmochim. Acta. 89, 134-158. doi:10.1016/j.gca.2012.04.037

Domagal-Goldman, S. D., and Wright, K. E. (Editors) (2016). The astrobiology primer v2.0. Astrobiology. 16 (8), 561-653. doi:10.1089/ast.2015.1460

Drouin, D., Couture, A. R., Joly, D., Tastet, X., Aimez, V., and Gauvin, R. (2007). CASINO V2.42-a fast and easy-to-use modelling tool for scanning electron microscopy and microanalysis users. Scanning. 29, 92-101. doi:10.1002/sca.20000

Fritz, J., Greshake, A., and Fernandes, V. A. (2017). Revising the shock classification of meteorites, Meteor. Planet Sci. 52 (6), 1216-1232. doi:10. $1111 /$ maps. 12845

Goldstein, J. I., and Doan, A. S. (1972). The effect of phosphorus on the formation of the Widmanstätten pattern in iron meteorites. Geochim. Cosmochim. Acta. 36, 51-69. doi:10.1016/0016-7037(72)90120-2

Goldstein, J. I., Williams, D. B., and Cliff, G. (1986). "Quantification of energy dispersive spectra," in Principles of analytical electron microscopy., Editors D. C. Joy, A. D. Romig, and J. L. Goldstein (New York, NY: Plenum Press), 155-217.

Gubbens, A., Barfels, M., Trevor, C., Twesten, R., Mooney, P., Thomas, P., et al. (2010). The GIF quantum, a next generation post-column imaging energy filter. Ultramicroscopy. 110, 962-970. doi:10.1016/j.ultramic.2010.01.009

Gyollai, I., Kereszturi, Á., and Chatzitheodoridis, E. (2019). Analysis of shock metamorphic processes in the Zagami meteorite. Central Eur. Geol. 62 (1), 56-82. doi:10.1556/24.61.2018.12

Hanesch, M. (2009). Raman spectroscopy of iron oxides and (oxy) hydroxides at low laser power and possible applications in environmental magnetic studies. Geophys. J. Int. 177 (3), 941-948.

Hunt, A. C., Cook, D. L., Lichtenberg, T., Reger, P. M., Ek, M., Golabek, G. J., et al. (2018). Late metal-silicate separation on the IAB parent asteroid: constraints from combined $\mathrm{W}$ and $\mathrm{Pt}$ isotopes and thermal modelling. Earth Planet Sci. Lett. 482, 490-500. doi:10.1016/j.epsl.2017.11.034

Jiruše, J., Hanicinec, M., Havelka, M., Hollricher, O., Ibach, W., and Spizig, P. (2014). Integrating focused ion beam-scanning electron microscope with confocal Raman microscope into a single instrument. J. Vac. Sci. Technol. B. 32 (6), 06FC03. doi:10.1116/1.4897502

Kemper, F., de Koter, A., Waters, L. B. F. M., Bouwman, J., and Tielens, A. G. G. M., (2002). Dust and the spectrat energy distribution of the OH/IR star OH $127.8+$ 0.0: evidence for circumstellar metallic iron, Astron. Astrophys. 384, 585-593. doi:10.1051/0004-6361: 20020036

Kereszturi, A., Gyollai, I., Kereszty, Zs., Kiss, K., Szabó, M., Szalai, Z., et al. (2017). Analyzing Raman-infrared spectral correlation in the recently found meteorite Csátalja. Spectrochim. Acta Part A. 173, 637-646. doi:10.1016/j. saa.2016.10.012

Kereszturi, A., Ormandi, S., and Josza, S. (2015). Possible melting produced chondrule distruction in NWA 6640 CK4 chondrite, Meteor. Planet Sci. 50 (7), 1295-1309. doi:10.1111/maps.12458

Kichanov, S., E., Kozlenko, D. P., Lukin, E. V., Rutkauska, A. V., Krasavin, E. A., Rozanov, A. Y., et al. (2018). A neutron tomography study of the Seymchan pallasite. Meteor. Planet Sci. 53 (10), 2155-2164. doi:10.1111/ maps. 13115
Lehmann, E. H., Peetermans, S., Trtik, P., Betz, B., and Grünzweig, C. (2017). New neutron imaging techniques to close the gap to scattering applications. J. Phys. Conf. 746 012070. doi:10.1088/1742-6596/746/1/012070

Lin, L. S., Goldstein, J. I., and Williams, D. B. (1977). Analytical electron study of the plessite structure in the Carlton iron meteorite. Geochem. Cosmochim. Acta. 41 (12), 1861-1874. doi:10.1016/0016-7037(77)90217-4.

Lo, Y. H., Liao, C. T., Zhou, J., Rana, A., Bevis, C. S., Gui, G., et al. (2019). Multimodal x-ray and electron microscopy of theAllende meteorite. Sci. Adv. 5, eaax3009. doi:10.1093/oxfordjournals.jmicro.a050593

Lodders, K., and Amari, S. (2005). Presolar grains from meteorites: remnants from the early times of the solar system. Chem. Erde. 65 (2), 93-166. doi:10.1016/j. chemer.2005.01.001

Messenger, S., Keller, L. P., Stadermann, F. J., Walker, R. M., and Zinner, E. (2003). Samples of stars beyond the solar system: silicate grains in interplanetary dust. Science. 300, 105-108. doi:10.1126/science. 1080576

Molster, F. J., Waters, L. B. F. M., Tielens, A. G. G. M., and Barlow, M. J., (2002a). Crystalline silicate dust around evolved stars. I. The sample stars. Astron. Astrophys. 382, 184-221. doi:10.1051/0004-6361:20011550

Molster, F. J., Waters, L. B. F. M., and Tielens, A. G. G. M., (2002b). Crystalline silicate dust around evolved stars. II. The crystalline silicate complexes. Astron. Astrophys. 382, 222-240. doi:10.1051/0004-6361:20011551

Molster, F. J., Waters, L. B. F. M., Tielens, A. G. G. M., Koike, C., and Chihara, H., (2002c). Crystalline silicate dust around evolved stars. III. A correlations study of crystalline silicate features. Astron. Astrophys. 382, 241-255. doi:10.1051/ 0004-6361:20011552

Ott, U., and Hoppe, P. (2006). "Presolar grains in meteorites and interplanetary dust: an overview," in Proccedings of 14TH XXVIth IAU General Assembly (Highlights of Astronomy), Prague, Czech Republic, August 1, 2006. Editor: Karel A. van der Hucht (Cambridge, UK: Cambridge Universtity Press), 341-344.

Ramsden, A. R., and Cameron, E. N. (1966). Kamacite and taenite superstructures and a metastable tetragonal phase in iron meteorites. Am. Miner. 51, 37-55. doi:10.1038/213166b0

Schlossmacher, P., Klenov, D. O., Freitag, B., and von Harrach, H. S. (2010). Enhanced detection sensitivity with a new windowless XEDS system for AEM based on silicon drift detector technology. Microsc. Today. 18, 14e20. doi:10. $1017 /$ s1551929510000404

Schmidt, R., Fitzek, H., Nachtnebel, M., Mayrhofer, C., Schroettner, H., and Zankel, A. (2019). The combination of electron microscopy, Raman microscopy and energy dispersive X-ray spectroscopy for the investigation of polymeric materials. Macromol. Symp. 384 (1), 1800237. doi:10.1002/ masy.201800237

Scott, E. R. D., and Wasson, J. T. (1976). Chemical classification of iron meteorites. VIII. Groups IC, IIE, IIIF, and 97 other irons. Geochim.et Cosmochim. Acta. 40, 103-115. doi:10.1016/0016-7037(76)90198-8

Skulteti, A., Kereszturi, A., Kereszty, Zs., Pal, B., Szabo, M., and Cipriani, F. (2020a). Role of spectral resolution for infrared asteroid compositional analysisusing meteorite spectra. MINRAS. 496, 689-694. doi:10.1093/ mnras/staa1475

Skulteti, A., Kereszturi, A., Szabod, M., Kereszty, Zs., and Cipriani(2020b). Midinfrared spectroscopic investigation of meteorites and perspectives forthermal infrared observations at the binary asteroid Didymos. Planet. Space Sci. 184, 104855. doi:10.1016/j.pss.2020.104855

Suh, K.-W., (2002). Crystalline silicates in the envelopes and discs around oxygenrich asymptotic giant branch stars. Mon. Not. Roy. Astron. Soc. 332, 513-528. doi:10.1046/j.1365-8711.2002.05303.x

Swart, P. K., Grady, M. M., Pillinger, C. T., Lewis, R. S., and Anders, E., (1983). Interstellar carbon in meteorites. Science. 220, 406-410. doi:10.1126/science. 220.4595.406

The Meteorite Exchange. (2014). The Scientific Study of meteorites, James Tobin, March 18 2014. Available at: https://www.meteorite.com/study-of-meteorites (Accessed March 11, 2020).

Tulej, M., Wiesendanger, R., Neuland, M., Meyer, S., Wurz, P., Neubeck, A., et al. (2017). Miniature laser mass spectrometer and optical microscopy: current capabilities for the quantitative analysis of micro-sized solid materials. EPSC Abstr. 11, 707. doi:10.5194/epsc2020-149 
Van Niekerk, D., Greenwood, R. C., Franchi, I. A., Scott, E. R. D., and Keil, K. (2007). Seymchan: a main group pallasite-not an iron meteorite. Meteor. Planet Sci. 42, A154. doi:10.18502/keg.vli1.4388

Vollmer, C., Kepaptsoglou, D., Leitner, J., Busemann, H., Spring, N. H., Ramasse, Q. M., et al. (2014). Fluid-induced organic synthesis in the solar nebula recorded in extraterrestrial dust from meteorites. Proc. Natl. Acad. Sci. U.S.A. 111 (43), 15338-15343. doi:10.1073/pnas.1408206111

Vollmer, C., Leitner, J., Kepaptsoglou, D., Ramasse, Q. M., Busemann, H., and Hoppe, P. (2019). Isotopic compositions, nitrogen functional chemistry, and low-loss electron spectroscopy of complex organic aggregates at the nanometer scale in the carbonaceous chondrite Renazzo. Meteor. Planet. Sci. 1, 27. doi:10. 1111/maps.13389

Wasson, J., and Wang, J. (1986). A nonmagnetic origin of group-IIE iron meteorites, Geochem. Cosmochim. Acta. 50, 725-732. doi:10.1016/00167037(86)90348-0

Wilson, G. C. (2012). Mineral chemistry, coarse pallasitic facies of the Seymchan meteorite. Available at: www.turnstone.ca/seymchan_EPM. pdf in http://www.turnstone.ca/rom127se.htm (Accessed March 11, 2020).

Yang, J., Goldstein, J. I., and Scott, E. R. D. (2010). Main-group pallasites: thermal history, relationship to IIIAB irons, and origin. Geochem. Cosmochim. Acta. 74, 4471-4492. doi:10.1016/j.gca.2010.04.016

Conflict of Interest: The authors declare that the research was conducted in the absence of any commercial or financial relationships that could be construed as a potential conflict of interest.

Copyright $\odot 2020$ Albu, Fitzek, Moser, Kothleitner and Hofer. This is an open-access article distributed under the terms of the Creative Commons Attribution License (CC $B Y$ ). The use, distribution or reproduction in other forums is permitted, provided the original author(s) and the copyright owner(s) are credited and that the original publication in this journal is cited, in accordance with accepted academic practice. No use, distribution or reproduction is permitted which does not comply with these terms. 